\title{
Using the AHP Method to Research the Cargo Stowage of Vehicles
}

\author{
http://dx.doi.org/10.3991/ijoe.v11i8.4885 \\ Xumei Zhang ${ }^{1}$ Shaohua $\mathrm{Wei}^{2}$ \\ ${ }^{1}$ Wuhan University of Science and Technology, Wuhan, China \\ ${ }^{2}$ Xi'an Technological University, Xi'an, China
}

\begin{abstract}
Cargo stowage is a nonlinear and complicated problem of multi-objective programming. How to load different batch numbers and varieties and different submitted locations and sizes of goods into a vehicle and deliver it to the user in a timely manner is a process that needs to be balanced; it is an optimization model with constraints. Considering the differences between types of goods are sizeable and unclear, it is reasonable to use an AHP to solve cargo stowage problems. In accordance with the requirements of vehicle loading characteristics, a corresponding hierarchy model is set up, the judgment matrix is constructed, the hierarchical order is sorted, the judgment matrix is validated through consistency checks, and finally the weight of each object in the hierarchy is obtained. Multiplying the weight by the corresponding score, the vehicle's total score is obtained. Comparing the total score of the alternative vehicles, the vehicle with the largest score is the loading vehicle, so the purpose of stowing the cargo is achieved.
\end{abstract}

Index Terms-AHP, judgment matrix, Cargo stowage

\section{INTRODUCTION}

According to the shipping plan proposed by the shipper, stowage makes the specific transport shift of the vehicle subordinate to the type, quantity and volume of the shipment of the goods. Based on transport supply and demand information, logistics enterprises find cargo for a vehicle, and the owner enterprises find vehicles for goods, which is commonly referred to as cargo stowage.

Cargo stowage is a nonlinear and complicated problem of multi-objective programming. How to load different batch numbers and varieties and different submitted locations and sizes of goods to the vehicle and deliver it in a timely manner to the user is a process that needs to be balanced; it is an optimization model with constraints. Considering the differences between types of goods is sizeable and unclear, it is reasonable to use an analytic hierarchy process (AHP) to solve cargo stowage problems.

AHP was formally put forward by T. L. Saaty, who was an operational research professor in the United States in the mid-1970s. It is a systematic and hierarchical analysis method that is the combination of qualitative and quantitative analysis. Because of the practicality and effectiveness in dealing with complex decision problems. Its application is in economic planning and management, energy policy and allocation, behavioral science, military command, transport, agriculture, education, talent, health and environment, etc.

AHP is a relatively mature theory, and there are a lot of practices and lessons that can be drawn from experience.
It makes thinking systematic and digital, promotes thought that is simple and clear, and is easy to calculate. Its biggest advantage is the organic combination of qualitative and quantitative analysis, which is effective for solving comprehensive evaluation problems in multi-level and multi-factor systems.

The steps of AHP are as follows:

Through deep understanding of the system, it is necessary to determine the overall goal of the system and to clearly identify the scope of the planning decisions as well as the measures and policies to be pursued and the goal of principles, policies, and various constraints, etc., and to widely collect information.

According to differences in the target and the function, it is necessary to build a multi-level hierarchical structure and divide the system into several grade levels and determine the related degree in adjacent level elements of the hierarchical structure. By constructing the comparative judgment matrix and mathematical methods of matrix operation it is possible to determine the importance order of the relevant elements for an element on a level, which is called relative weights.

Then it is necessary to calculate the synthetic weight of the layers of elements on the system target to determine the degree of the overall goal on hierarchical structure.

Consistency check.

According to the analysis and calculation results, the next step is to consider the corresponding decision. But the subjectivity of AHP is stronger; the reason is that the structure of the judgment matrix is mainly produced by an expert investigation method, which mainly depends on the expert's subjective judgment. There may be not objective and comprehensive evaluation of each scheme, which eventually leads to inaccurate evaluation results. In addition, this method can only be given to choose optimal solutions or strategies and is unable to provide a new strategy or plan. When the scale of the problem is larger and is affected by many factors, the method is easy for identifying problems (e.g., judgment matrix consistency issues). Therefore, in vehicle loading, it is necessary to combine the AHP method with other methods to make decisions aboout vehicle stowage to ensure the accuracy of the results. In the expert scoring, by adopting a quantitative method to select the experts and calculating the expert evaluation, the analysis results will be more reasonable.

Selection of experts can be based on the entropy theory, as follows:

Under the influence of uncertainty factors in incomplete information, the time needed for evaluation, personal 
preferences, and the target recognition degree of the expert scoring results is large. Because entropy is the best measure of uncertainty, it can be used to evaluate the uncertainty of the results and establish the given information quality of the evaluation experts and the entropy model of expert selection.

Assuming there is an ideal optimal expert, its grade is the most fair and accurate. Through actual calculation and determination, you can choose the one with the greatest consistency for understanding the evaluation objects with the highest experts, namely the smallest difference in experts to the overall. This gap is expressed in entropy.

Expert evaluation methods are:

\section{A. Addition evaluation model}

Evaluate the sum score obtained, which is the score evaluation result. This method is used to identify the simple index relationship.

Formula is:

$$
w=\sum_{i=1}^{n} w_{i}
$$

Among them:

$\mathrm{W}$ - total score of evaluation object;

$\mathrm{Wi}$ - the ith indicators score;

$\mathrm{N}$ - index number.

\section{B. Multiplied evaluation model}

Multiply the score in each project and show the results according to the product size. This method is of high sensitivity and is especially close between the various indicators of the evaluation objects. And a total score jointly affects other results, namely while an index is unqualified, the characteristics of the negative will affect the whole.

Formula is:

$$
w=\prod_{i=1}^{n} w_{i}
$$

Among them:

$\mathrm{W}$ - total score of evaluation object;

$\mathrm{Wi}$ - the ith indicators score;

$\mathrm{N}$ - index number.

\section{Multiplied addition evaluation model}

The evaluation indexes of the evaluation objects can be divided into several groups and then calculate each score value first and multiply each score value, which is the total score.

Formula is:

$$
w=\prod_{i=1}^{m} \sum_{j=1}^{n} w_{i}
$$

Among them:

$\mathrm{Wij}$ - the index value I to $\mathrm{J}$ in the evaluation objects;

$\mathrm{M}$ - group number of evaluation objects;

$\mathrm{N}$ - index number in I group.

In accordance with the requirements of vehicle loading characteristics, the corresponding hierarchy model is set up. Then the judgment matrix is constructed and the hierarchical order sorting is completed, the judgment matrix is validated by a consistency check, and the weight of each object hierarchy is finally obtained. By multiplying the weight by the corresponding score, the vehicle's total score is obtained. Comparing the total score of the alternative vehicles, the vehicle with the largest score is the loading vehicle.

\section{Establish THE HiERARCHY StRUCTURE DIAGRAM}

The method of establishing a hierarchical structure diagram is to classify related factors of the problem first and then to establish a hierarchical structure diagram of which factors are connected to each other. The factor classification of the model is as follows: first one is the target class A, which is to choose the most optimal vehicles for cargo. The criterion of the second is class B, which is goal realization standards to measure "cargo for vehicle." The third measure is class $\mathrm{C}$, which is to achieve a target scheme, method and means, etc. The model of "cargo for vehicle" hierarchical structure diagram is as shown in Figure 1.

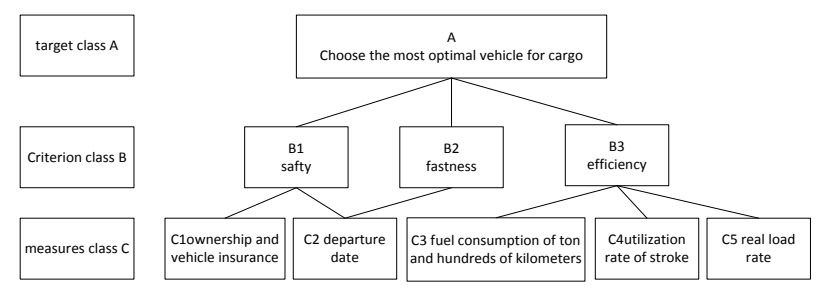

Figure 1 hierarchical structure diagram of cargo stowage

\section{CONSTRUCT The JUdGMENT MATRIX AND} COMPLETE THE HIERARCHICAL ORDER SORTING

Constructing the judgment matrix is the most critical step in AHP, which is also the starting point. The formation of the judgment matrix is a quantification process of people's subjective thinking and is the basis of the analysis of the problem. In decision analysis, the target layer is under the influence of the three standards factors, which are influenced by each decision factor. According to the relative importance comparison between the last hierarchy factors and the current hierarchical factors, the judgment matrix is constructed. The importance of the comparison is done by the description of the scale; a scale of 1 to 9 is introduced in the AHP method. In "cargo for vehicle" model, such as A layer of "choose the optimal vehicle for cargo," is associated with safety, speed, and efficiency in $\mathrm{B}$ layer, and then the judgment matrix $\mathrm{A} \square \mathrm{B}$ is constructed. Among them, the $\mathrm{Bij}$ means $\mathrm{Bi}$ relative importance of $\mathrm{Bi}$ to $\mathrm{Bj}$ for $\mathrm{A}$. The option of $\mathrm{Bij}$ is 1 to 9 or the reciprocal 1 to $1 / 9$. As is shown in Table1.

$$
\text { Obviously, bij = } 1(I=\mathrm{j}), \mathrm{bji}=1 / \text { bij }(I, \mathrm{j})(\mathrm{i} \text { j) }
$$

TABLE I. TYPE SIZES FOR CAMERA-READY PAPERS

\begin{tabular}{|l|c|}
\hline \multicolumn{1}{|c|}{ Comparison importance judgment } & Quantitative values \\
\hline Equally important & 1 \\
\hline Weakly important & 3 \\
\hline More important & 5 \\
\hline Highly important & 7 \\
\hline Extremely important & 9 \\
\hline Importance between two adjacent judgments & $2,4,6,8$ \\
\hline
\end{tabular}


Then complete the levels of single sorting, a sum and product method is used to solve the maximum eigenvalue and feature vectors; first each column of the judgment matrix is normalized as in (4):

$$
\mathbf{b}_{i j}^{\prime}=\frac{b_{i j}}{\sum_{i=1}^{n} b_{i j}}
$$

$\mathrm{i}=1,2, \ldots, \mathrm{n}$

$\mathrm{j}=1,2, \ldots, \mathrm{n}$

Then sum the normalized matrix according to the lineup as in (5):

$$
\overline{\mathrm{b}_{i}}=\sum_{j=1}^{n} b_{i j}^{\prime}
$$

$$
\begin{aligned}
& \mathrm{i}=1,2, \ldots, \mathrm{n} \\
& \mathrm{j}=1,2, \ldots, \mathrm{n}
\end{aligned}
$$$$
\bar{b}
$$

And then normalize $\bar{b}_{i}$ and find the feature vector $\overline{W_{1}}=\left(\overline{W_{1}}, \overline{W_{2}}, \ldots, \overline{W_{n}}\right)^{T}$ as in (6)

$$
W_{i}=\frac{\overline{b_{i}}}{\sum_{i=1}^{n} \overline{b_{i}}}
$$

$$
\mathrm{i}=1,2, \ldots, \mathrm{n}
$$

At last the maximum eigenvalue is solved as in (7):

$$
\lambda_{\max }=\sum_{i=1}^{n} \frac{(b W)_{i}}{n W_{i}}
$$

$$
\mathrm{i}=1,2, \ldots, \mathrm{n}
$$

The judgment matrix of this model beside the maximum eigenvalue and feature vectors is as follows:

\section{A. judgment matrix $A-B$}

To achieve the target "choose the optimal vehicles for cargo," the importance comparison of various criteria such as safety, efficiency and speed is as shown in Table 2. And according to the above formula obtains the corresponding maximum eigenvalue $\lambda_{\max }$ and feature vectors $W=\left(W_{A B 1}, W_{A B 2}, W_{A B 3}\right)^{T}$.

\section{B. judgment matrix $B 1-C$}

To achieve the criteria of safety, the importance comparison of the relevant factors index is as shown in Table 3 . And using the above formula obtains the corresponding maximum eigenvalue $\lambda_{\max }$ and feature vectors $W=\left(W_{B 1 C 1}, W_{B 1 C 2}\right)^{T}$.

\section{C. judgment matrix B2-C}

To achieve the criteria of efficiency, the importance comparison of relevant factors index is as shown in Table 4. And using the above formula obtains the corresponding maximum eigenvalue $\lambda_{\max }$ and feature vectors $W=\left(W_{B 2 C 3}, W_{B 2 C 4}, W_{B 2 C 5}\right)^{T}$.
TABLE II.

JUDGMENT MATRIX A-B

\begin{tabular}{|c|c|c|c|}
\hline $\mathrm{A}$ & $\mathrm{B}_{1}$ & $\mathrm{~B}_{2}$ & $\mathrm{~B}_{3}$ \\
\hline $\mathrm{B}_{1}$ & $\mathrm{~b} 11$ & $\mathrm{~b} 12$ & $\mathrm{~b} 13$ \\
\hline $\mathrm{B}_{2}$ & $\mathrm{~b} 21$ & $\mathrm{~b} 22$ & $\mathrm{~b} 23$ \\
\hline $\mathrm{B}_{3}$ & $\mathrm{~b} 31$ & $\mathrm{~b} 32$ & $\mathrm{~b} 33$ \\
\hline
\end{tabular}

TABLE III. JUDGMENT MATRIX B1-C

\begin{tabular}{|c|c|c|}
\hline $\mathrm{B}_{1}$ & $\mathrm{C}_{1}$ & $\mathrm{C}_{2}$ \\
\hline $\mathrm{C}_{1}$ & $\mathrm{C} 11$ & $\mathrm{C} 12$ \\
\hline $\mathrm{C}_{2}$ & $\mathrm{C} 21$ & $\mathrm{C} 22$ \\
\hline
\end{tabular}

TABLE IV. JUDGMENT MATRIX B2-C

\begin{tabular}{|c|c|c|c|}
\hline $\mathrm{B}_{2}$ & $\mathrm{C}_{3}$ & $\mathrm{C}_{4}$ & $\mathrm{C}_{5}$ \\
\hline $\mathrm{C}_{3}$ & $\mathrm{C} 33$ & $\mathrm{C} 34$ & $\mathrm{C} 35$ \\
\hline $\mathrm{C}_{4}$ & $\mathrm{C} 43$ & $\mathrm{C} 44$ & $\mathrm{C} 45$ \\
\hline $\mathrm{C}_{5}$ & $\mathrm{C} 53$ & $\mathrm{C} 54$ & $\mathrm{C} 55$ \\
\hline
\end{tabular}

D. judgment matrix $B 3-C$

For the importance comparison of the relevant factors index to identify the criteria of speed, you can find only one factor index under the criteria from Figure 1. And using the above formula obtains the corresponding maximum eigenvalue $\lambda_{\max }$ and feature vectors $W=(1)^{T}$.

\section{THE CONSISTENCY CHeCK}

AHP is used to quantify the qualitative thinking process. However, when comparing the two complicated factors, it is impossible to make the judgment consistent. Estimation error can directly lead to the deviation of eigenvalue and feature vectors. The check is as follows:

Find the judgment matrix $\lambda_{\max }$ to $\mathrm{CI}$ and obtain the CI value, which is a consistency check index. When the judgment matrix is completely consistent, $\mathrm{CI}=0$. In order to measure if different degree number judgment matrix is of consistency, the average random index RI of the judgment matrix is introduced, as is shown in Table 5.

So we have the consistency of interpretation matrix CR; its calculation formula is:

$$
\mathrm{CR}=\mathrm{CI} / \mathrm{RI}
$$

Then we calculate the average value of the consistency index, namely CR, when CR is not more than 0.1 . The judgment matrix is reasonable, which means it has the right weight coefficient. Otherwise the judgment matrix will be adjusted and recalculated to the eight coefficient matrix according to the previous step. The calculation formula is as shown below:

$$
C I=\left(\lambda_{\max }-n\right) /(n-1)
$$

\section{OBTAIN THE WEIGHT}

For the last level, the process of use is associated with the weight of all the elements and the level of the weight of elements computed in view of the overall goal of the hierarchy weights of all the factors, called obtaining the weight. The process begins at the highest level; therefore, we can obtain the weight that the various factors of the son rule layer $\mathrm{C}$ to the total target $\mathrm{A}$, namely $W=\left(W_{A C 1}, W_{A C 2}, W_{A C 3}, W_{A C 4}, W_{A C 5}\right)^{T}$ and its calculation formula is: 
PAPER

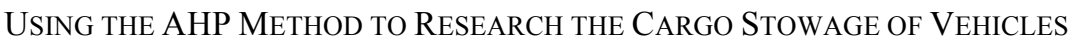

TABLE V. INDEX RI VALUE OF $1 \sim 9$ DEGREE JUDGMENT MATRIX

\begin{tabular}{|c|c|c|c|c|c|}
\hline Degree $\mathrm{n}$ & 1 & 2 & 3 & 4 & 5 \\
\hline RI & 0.00 & 0.00 & 0.58 & 0.90 & 1.12 \\
\hline Degree $\mathrm{n}$ & 6 & 7 & 8 & 9 & \\
\hline RI & 1.24 & 1.32 & 1.41 & 1.45 & \\
\hline
\end{tabular}

TABLE VI. SPECIFIC WEIGHTS

\begin{tabular}{|c|c|c|c|c|}
\hline $\mathrm{B}$ & $\mathrm{B}_{1}$ & $\mathrm{~B}_{2}$ & $\mathrm{~B}_{3}$ & Total weight \\
$\mathrm{C}$ & $\mathrm{W}_{\mathrm{AB} 1}$ & $\mathrm{~W}_{\mathrm{AB} 2}$ & $\mathrm{~W}_{\mathrm{AB} 3}$ & $\mathrm{~W}$ \\
\hline $\mathrm{C}_{1}$ & $\mathrm{~W}_{\mathrm{B} 1 \mathrm{C} 1}$ & 0 & 0 & $\mathrm{~W}_{\mathrm{AC} 1}$ \\
\hline $\mathrm{C}_{2}$ & $\mathrm{~W}_{\mathrm{B} 1 \mathrm{C} 2}$ & 0 & $\mathrm{~W}_{\mathrm{B} 3 \mathrm{C} 2}$ & $\mathrm{~W}_{\mathrm{AC} 2}$ \\
\hline $\mathrm{C}_{3}$ & 0 & $\mathrm{~W}_{\mathrm{B} 2 \mathrm{C} 3}$ & 0 & $\mathrm{~W}_{\mathrm{AC} 3}$ \\
\hline $\mathrm{C}_{4}$ & 0 & $\mathrm{~W}_{\mathrm{B} 2 \mathrm{C} 4}$ & 0 & $\mathrm{~W}_{\mathrm{AC} 4}$ \\
\hline $\mathrm{C}_{5}$ & 0 & $\mathrm{~W}_{\mathrm{B} 2 \mathrm{C}}$ & 0 & $\mathrm{~W}_{\mathrm{AC} 5}$ \\
\hline
\end{tabular}

$\mathrm{WAC} 1=\mathrm{WAB} 1 * \mathrm{WB} 1 \mathrm{C} 1$

$\mathrm{WAC} 2=\mathrm{WAB} 1 * \mathrm{WB} 1 \mathrm{C} 2+\mathrm{WAB} 3 * \mathrm{WB} 3 \mathrm{C} 2$

$\mathrm{WAC} 3=\mathrm{WAB} 2 * \mathrm{WB} 2 \mathrm{C} 3$

$\mathrm{WAC} 4=\mathrm{WAB} 2 * \mathrm{WB} 2 \mathrm{C} 4$

$\mathrm{WAC} 5=\mathrm{WAB} 2 * \mathrm{WB} 2 \mathrm{C} 5$

The specific weights are seen in Table 6 .

\section{Determine The Vehicle Of Stowage The CARGO}

According to the specific circumstances of each matching car, each index is given a score according to the specific scoring rules. Then the score is multiplied by the corresponding weights. Finally, they are combined to get a total score, and the vehicle ranked first is the best match.

A specific integral rule to the problem of the "cargo for vehicle" is as follows:

\section{A. The ownership and vehicle insurance scoring $C 1$}

Adopting a one hundred mark system, the general scoring class is set to a value as follows.

State-run 60; Collective 40; Individual 20; Car insurance 40 .

\section{B. Departure date scoring $C 2$}

Adopting a one hundred mark system, the specific score is determined according to the actual situation.

When the departure date and time of shipment are on the same day, the score is 100 ;

When departure date and time of shipment are on the second day, the score is 60 ;

When the departure date and delivery date are on the third day, the score is 20;

The others are out of consideration, so the score is 0 .

\section{Scoring of fuel consumption of ton and hundreds of kilometers $C 3$}

Set up the fuel consumption for hundreds of kilometers $\mathrm{X}$ liters

$$
\mathrm{C} 3=100-(\mathrm{X}-2) * 10
$$

\section{Scoring of utilization rate of stroke C4}

$$
\mathrm{C} 4=\text { utilization rate of stroke } * 100
$$

When the total stroke is longer than the distance between the destination and the city, it shows that it is a drop shipment and shall not be considered.

\section{E. Real load rate scoring $C 5$}

real load rate $=$ weight $/$ deadweight load rate . while the load weight $<$ dead weight:

C5 $=$ real load rate $* 100$

while the load weight $>$ dead weight:

$\mathrm{C} 5=100 /$ real load rate -20

F. A total score of $C$

$\mathrm{C}=\mathrm{WAC} 1 * \mathrm{C} 1+\mathrm{WAC} 2 * \mathrm{C} 2+\mathrm{WAC} 3 * \mathrm{C} 3+\mathrm{WAC} 4 * \mathrm{C} 4+$

$$
\mathrm{WAC} 5 * \mathrm{C} 5
$$

The highest total score of $\mathrm{C}$ is the best match.

\section{CONCLUSION}

Considering the differences between types of goods are sizeable and unclear, it is reasonable to use an AHP to solve cargo stowage problems. In accordance with the requirements of vehicle loading characteristics, a corresponding hierarchy model is set up. Then the judgment matrix is constructed and the hierarchical order sorting is completed, judgment matrix is validated by consistency check, and the weight of each object hierarchy is finally obtained. The score of the objects in the measure class, which are ownership and vehicle insurance $\mathrm{C} 1$, departure date $\mathrm{C} 2$, fuel consumption of ton and hundreds of kilometers $\mathrm{C} 3$, utilization rate of stroke $\mathrm{C} 4$, and real load rate $\mathrm{C} 5$, is given by the specific calculation formula. By multiplying the weight by the corresponding score, the vehicle's total score is obtained. By comparing the total score of alternative vehicles, the vehicle with the highest score is the loading vehicle and the purpose of the cargo stowage is achieved.

\section{ACKNOWLEDGMENT}

We gratefully acknowledge the excellent comments made by the reviewers.

\section{REFERENCES}

[1] Khan, K. A., Yunt, M, Barton, P., I., 2011. Global Optimization of Nonsmooth Dynamic Systems.Proceedings of the 2011 AIChE Annual Meeting.

[2] Kolda, T. G., Lewis, R. M., Torczon, V., 2003. Optimization by Direct Search: new Perspectives on some classical and modern methods. SIAM Rev., 45, pp. 385-482. http://dx.doi.org/10.1137/S003614450242889

[3] Kolda, T. G., Lewis, R. M., Torczon, V., 2006a. Stationarity Results for Generating Set Search for Linearly Constrained Optimization. SIAM Journal on Optimization, 17, pp. 943-968. http://dx.doi.org/10.1137/S1052623403433638

[4] Kolda, T. G., Lewis, R. M., Torczon, V., 2006b. A Generating Set Direct Search Augmented Lagrangian algorithm for Optimization with a Combination of General and Linear Constraints. SANDIA Report SAND2006-5315.

\section{AUTHORS}

Xumei Zhang is with Wuhan University of Science and Technology, Wuhan, China.

Shaohua Wei is with Xi'an Technological University North Institute of Information Engineering, Xi'an, China.

This study is supported by the Natural Science Foundation of China (NSFC) under Grant No. 51275365 and the school funding from Wuhan University of Science and Technology under Grant No.250089 and open funding from Wuhan University of Science and Technology under Grant No.C1009 and Hubei Province Collaborative Innovation Center for Automotive Part and Assembly Technology. Submitted 21 July 2015. Published as resubmitted by the authors 10 October 2015. 